\title{
Ventral Tegmental Afferents in Stress-Induced Reinstatement: The Role of cAMP Response Element-Binding Protein
}

\author{
Lisa A. Briand, ${ }^{1}$ Fair M. Vassoler, ${ }^{2}$ R. Christopher Pierce, ${ }^{2}$ Rita J. Valentino, ${ }^{3 *}$ and Julie A. Blendy ${ }^{1 \star}$ \\ Departments of ${ }^{1}$ Pharmacology and ${ }^{2}$ Psychiatry, The University of Pennsylvania School of Medicine, Philadelphia, Pennsylvania 19104, and ${ }^{3}$ Department of \\ Anesthesiology and Critical Care Medicine, Children's Hospital of Philadelphia, Philadelphia, Pennsylvania 19104
}

The transcription factor cAMP response element-binding protein (CREB) is required for stress- but not drug-induced reinstatement of cocaine conditioned place preference. To reveal the neural circuitry associated with this CREB dependence, we injected a retrograde tracer into the ventral tegmental area (VTA) and identified afferents that were activated after stress or cocaine exposure in both naive and cocaine-conditioned mice. Neuronal activation, as assessed by Fos expression, was greatly reduced in the dorsal and ventral bed nucleus of the stria terminalis (BNST), lateral septum, and nucleus accumbens shell in mice lacking CREB (CREB $\alpha \Delta$ mice) after a 6 min swim stress but not after cocaine exposure $(20 \mathrm{mg} / \mathrm{kg})$. Additionally, activation of VTA afferent neurons in the ventral BNST and the infralimbic cortex in CREB $\alpha \Delta$ mice was blunted in response to stress. This pattern of neuronal activation persisted in mice that were conditioned to a cocaine place preference procedure before stress exposure. Furthermore, lidocaine inactivation $(0.4 \mu \mathrm{l}, 4 \%)$ studies demonstrated the necessity of BNST activation for swim-stress-induced reinstatement of cocaine-conditioned reward. Together, the present studies demonstrate that CREB is required for the activation of a unique circuit that converges on the dopamine reward pathway to elicit reinstatement of drug reward and points to the BNST as a key intersection between stress and reward circuits.

\section{Introduction}

Clinical research indicates that life stress is not only a risk factor in the development of addiction but also a trigger for relapse to drug use (Brown et al., 1990; McFall et al., 1992; Brown et al., 1995; Dewart et al., 2006; Ouimette et al., 2007). Preclinical studies using both cocaine conditioned place preference and cocaine self-administration reinstatement models have demonstrated that stress exposure reinstates cocaine-seeking behavior in animals that have undergone extinction. Using immediate early gene expression, imaging, and reversible inactivation of specific nuclei, the bed nucleus of the stria terminalis (BNST), central nucleus of the amygdala (CeA), and the nucleus accumbens (NAc) shell have been identified as key components of stress-induced reinstatement circuitry (Erb et al., 2001; Lu et al., 2002; see Shaham et al., 2003 for review; McFarland et al., 2004; Wang et al., 2006). Furthermore, these regions impinge on a final common pathway that is thought to mediate drug-induced reinstatement (McFarland and Kalivas, 2001; McFarland et al., 2004; Kalivas and Volkow, 2005; Peters et al., 2008). The ventral tegmental area (VTA), the source of dopamine that projects to the medial prefrontal cortex and NAc, receives afferents from the BNST, central nucleus of amygdala, and NAc shell (Geisler and

Received June 3, 2010; revised Sept. 24, 2010; accepted Sept. 24, 2010.

This work was supported by National Institute on Drug Abuse Grants DA011649 (J.A.B.) and F32 DA026660 (L.A.B.). We thank Thelma Bethea for technical assistance.

*R.J.V. and J.A.B. contributed equally to this work.

Correspondence should be addressed to Dr. Julie A. Blendy, Department of Pharmacology, University of Pennsylvania, Translational Research Laboratories, 125 South 31st Street, Philadelphia, PA 19104. E-mail: blendy@mail.med.upenn.edu.

DOI:10.1523/JNEUROSCI.2827-10.2010

Copyright $\odot 2010$ the authors $\quad 0270-6474 / 10 / 3016149-11 \$ 15.00 / 0$
Zahm, 2005). Activation of VTA-projecting neurons by these afferents may be a means by which stress engages reward circuitry. Within the VTA, activation of corticotropin-releasing factor (CRF) type 2 receptors is necessary for stress-induced reinstatement (Wang et al., 2007). Additionally, infusion of CRF agonists into the VTA elicits reinstatement of drug seeking (Wang et al., 2007). However, the precise mechanisms linking stress-activated neurons in these regions with drug reward circuitry has not been established.

At the cellular level, molecular events underlying stressinduced reinstatement are not well characterized. Chronic drug exposure induces adaptive changes in the CNS that lead to drug dependence (Nestler, 2005, 2008). The long-lasting nature of addiction indicates that changes in gene expression may be necessary for its development and persistence. The transcription factor cAMP response element-binding protein (CREB) has been implicated in the long-term neuronal plasticity associated with many behaviors, including addiction (Nestler et al., 1993). Specifically, cocaine activates CREB within brain regions related to addiction, including prefrontal cortex, NAc, and VTA (Walters et al., 2003; Fumagalli et al., 2007; Nazarian et al., 2009). Additionally, both acute and chronic stress can increase phosphorylated CREB in brain regions involved in stress-induced reinstatement, including the NAc, CeA, BNST, hippocampus, and frontal cortex (Curtis et al., 2002; Kwon et al., 2006; Xu et al., 2006; Blundell and Adamec, 2007; Kreibich et al., 2009).

A role for CREB in stress-induced reinstatement is underscored by our findings that cocaine conditioned place preference (CPP) is reinstated by stress in wild-type mice but not in mice lacking the $\alpha$ and $\Delta$ isoforms of $\operatorname{CREB}(\operatorname{CREB} \alpha \Delta)$. In contrast, a priming injection of cocaine reinstates cocaine CPP in both wild- 
type and CREB $\alpha \Delta$ mice (Kreibich and Blendy, 2004). These findings suggest that stress is unique in specifically engaging reward circuitry in a CREB-dependent manner. The present study combined retrograde tract tracing with Fos immunohistochemistry to identify populations of neurons engaged by stress during the process of reinstatement that converge on the VTA. Comparisons of this activated circuitry between wild-type and CREB mutant mice revealed the CREB-dependent circuits underlying stressinduced reinstatement. Finally, local cellular inactivation studies demonstrated the necessity of the BNST for swim-stress-induced reinstatement of cocaine-conditioned reward in mice. Together, this information advances our understanding of systems and molecular aspects of circuits underlying stress-induced drug relapse.

\section{Materials and Methods}

\section{Experiment I}

Subjects. A total of 25 CREB $\alpha \Delta$ mutant mice and 25 sex- and agematched wild-type littermates, bred and maintained on an F1 hybrid background (129SvEvTac/C57BL/6NTac) as described previously (Walters and Blendy, 2001), were group housed with food and water available ad libitum. All animals (2-4 months of age) were housed in a temperature- and humidity-controlled animal care facility with a $12 \mathrm{~h}$ light/dark cycle (lights on at 7:00 A.M.). All procedures were approved by the University of Pennsylvania Animal Care and Use Committee.

Tracer infusions. Mice were deeply anesthetized with isoflurane and positioned in a stereotaxic apparatus with the skull horizontal. A scalp incision was made and a hole was drilled centered at $3.4 \mathrm{~mm}$ caudal to bregma and $-0.3 \mathrm{~mm}$ lateral (right side). Single-barrel glass micropipettes (10-20 $\mu \mathrm{m}$ diameter) were backfilled with the retrograde tracer Fluorogold (FG) (2-4\% in saline; Fluorochrome) and positioned at the above coordinates and $4.4 \mathrm{~mm}$ ventral to the skull surface. FG was iontophoresed $(5 \mu \mathrm{A}, 5 \mathrm{~s}$ on and $5 \mathrm{~s}$ off for $15 \mathrm{~min})$ into the VTA. The pipette was left in place for $5 \mathrm{~min}$ after iontophoresis. After removing the pipette, the skin was sutured and mice were kept warm until they had fully recovered from anesthesia.

Acute stress or cocaine exposure. Seven to $10 \mathrm{~d}$ after FG injection, mice were either given an acute forced-swim stress exposure or acute cocaine injection or were taken from their home cage for transcardial perfusion. For swim stress, mice were placed for $6 \mathrm{~min}$ in plastic cylinders $(23 \mathrm{~cm}$ tall $\times 14 \mathrm{~cm}$ diameter) containing $23-25^{\circ} \mathrm{C}$ water that was $10 \mathrm{~cm}$ deep. Behavior was scored online using ViewPoint VideoTrack analysis software (ViewPoint Life Sciences). The acute cocaine animals were given a single intraperitoneal injection of $20 \mathrm{mg} / \mathrm{kg}$ cocaine. Acute stress and cocaine administration occurred 25 min before transcardial perfusion. Control animals were taken directly from their home cage without any stress exposure.

Tissue collection. Mice were deeply anesthetized with sodium pentobarbital $(10 \mathrm{mg} / \mathrm{kg})$ and transcardially perfused with $30 \mathrm{ml}$ of PBS, followed by $40 \mathrm{ml}$ of $4 \%$ paraformaldehyde in PBS. The brains were removed and placed in the same fixative overnight at $4^{\circ} \mathrm{C}$. Brains were then placed in a solution of $30 \%$ sucrose in PBS containing $0.1 \%$ sodium azide at $4^{\circ} \mathrm{C}$ for at least $48 \mathrm{~h}$ and frozen on dry ice. Forty micrometer sections from regions of interest were placed in PBS with $0.1 \%$ sodium azide and stored at $4^{\circ} \mathrm{C}$ until further processing.

Immunohistochemistry. Before immunohistochemical labeling, sections were incubated for $20 \mathrm{~min}$ in $0.75 \% \mathrm{H}_{2} \mathrm{O}_{2}$ in PBS, followed by several rinses in PBS. Sections were then rinsed several times with PBS containing $0.3 \%$ Triton X-100 (PBST) and $0.04 \%$ bovine serum albumin (BSA) before incubation in rabbit anti-Fos (Abcam). Sections were incubated for $3 \mathrm{~d}$ at $4^{\circ} \mathrm{C}$ in Fos primary antisera (1:1000) diluted in PBST plus BSA containing $0.1 \%$ sodium azide. Sections were rinsed several times in PBST plus BSA before $90 \mathrm{~min}$ incubation in secondary antisera (1:200, biotinylated donkey anti-rabbit; Jackson ImmunoResearch). After additional rinses, sections were incubated in avidin-biotin complex (ABC elite kit; Vector Laboratories) for $90 \mathrm{~min}$. After PBS rinses, sections were incubated for $5 \mathrm{~min}$ in $0.04 \%$ 3,3' -diaminobenzidine- $4 \mathrm{HCl}$ (DAB) (Sigma) containing $0.01 \% \mathrm{H}_{2} \mathrm{O}_{2}$ and $0.06 \%$ nickel sulfate in Tris buffer for a black reaction product that was terminated by rinses in PBS. Sec- tions that were processed for FG dual labeling were incubated in $0.75 \%$ $\mathrm{H}_{2} \mathrm{O}_{2}$ in PBS (20 min) after processing for Fos immunoreactivity. The sections were rinsed in PBS and incubated for $2 \mathrm{~d}$ at $4^{\circ} \mathrm{C}$ in rabbit anti-FG (1:2000; Millipore). Sections were rinsed and processed as described above for Fos using the $\mathrm{ABC}$ elite kit. After rinsing, immunolabeling was visualized using $0.04 \% \mathrm{DAB}$ containing $0.01 \% \mathrm{H}_{2} \mathrm{O}_{2}$ in $\mathrm{PB}$ for a brown reaction product. After processing, sections were mounted on glass slides, dehydrated, and coverslipped. Immunoreactivity was visualized using a Nikon Eclipse E600 microscope, and images were captured with a QImaging Retiga 1300 using Image-Pro Plus software (MediaCybernetics).

Data analysis. Fos-immunolabeled profiles from each brain region were quantified bilaterally from at least two sections per mouse and averaged. The person quantifying was blind to group assignments. Anatomical regions were identified according to the stereotaxic atlas of Franklin and Paxinos (2007). Single-labeled Fos images were quantified using NIH ImageJ software. Double-labeled Fos and FG images were counted manually. Only cases in which FG injections filled the VTA were used for quantification of double-labeled neurons (Fig. 1) (for example photomicrographs of double-labeled cells, see Fig. 5).

Statistical analyses. The number of single- or double-labeled cells in each brain region was determined for each animal. Group differences in Fos immunoreactivity or Fos/FG double-labeled cells were assessed using two-way ANOVAs with condition (stress or cocaine vs control) and genotype as the independent variables and number of cells as the dependent variable. Bonferroni's post hoc comparisons were conducted when main effects or interactions were present. Behavior during the swim stress was compared between wild-type and CREB mutant mice using an unpaired $t$ test with genotype (mutant and wild-type) as the independent variable and total time spent immobile as the dependent variable.

\section{Experiment II}

Subjects. A total of 39 CREB $\alpha \Delta$ mutant mice and 39 sex- and agematched wild-type littermates, bred and maintained on an F1 hybrid background (129SvEvTac/C57BL/6NTac) as described previously (Walters and Blendy, 2001), were group housed with food and water available ad libitum. All animals (2-4 months of age) were housed in a temperatureand humidity-controlled animal care facility with a $12 \mathrm{~h}$ light/dark cycle (lights on at 7:00 A.M.). All procedures were approved by the University of Pennsylvania Animal Care and Use Committee.

Conditioned place preference. On day 1 , mice were allowed to explore both sides of an unbiased two-chambered CPP apparatus $(20 \times 20 \times 20$ $\mathrm{cm}$ ) for $900 \mathrm{~s}$, and time spent in each side was recorded. These data were used to separate animals into groups with approximately equal biases for each side. Beginning on day 2 , animals were paired for $8 \mathrm{~d}$, with the saline group receiving injections ( $0.9 \%$ sodium chloride) on both sides of the boxes, whereas the drug-paired group received cocaine $(20 \mathrm{mg} / \mathrm{kg})$ on one side and saline on the other side. Drug-paired sides were randomized among all groups. After conditioning, animals were all given a saline injection and allowed to explore freely between the two sides, and time spent on each side was recorded. The preference score (time spent in drug-paired side minus time in saline-paired side) was calculated for each mouse. After the preference test, animals underwent extinction training during which saline was paired with both sides of the box for a total of $12 \mathrm{~d}$. On the extinction test day, the time spent on each side was recorded.

Tracer infusions. Mice underwent surgery in the middle of the extinction training and were given $3 \mathrm{~d}$ to recover from surgery before resuming extinction sessions. The methods were identical to those described for Experiment I.

Acute stress exposure. On the day after the extinction test, mice were either exposed to a $6 \mathrm{~min}$ swim stress (as described above) $20 \mathrm{~min}$ before transcardial perfusion or taken directly from their home cages.

Tissue collection, immunohistochemistry, and data analysis. Tissue collection, immunohistochemistry, and data analysis were as described for Experiment I.

Statistical analysis. The ability of cocaine to induce place preference behavior as well as the ability of extinction training to eliminate this preference was assessed using two-way ANOVA with drug (cocaine vs saline) and genotype (mutant vs wild-type) as the independent variables 
a vBNST

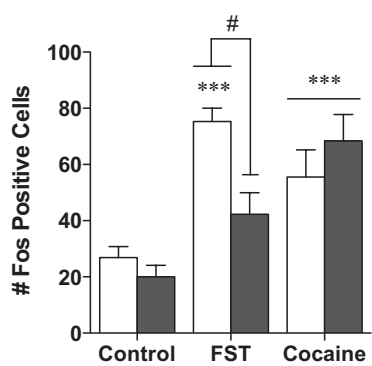

C Lateral Septum

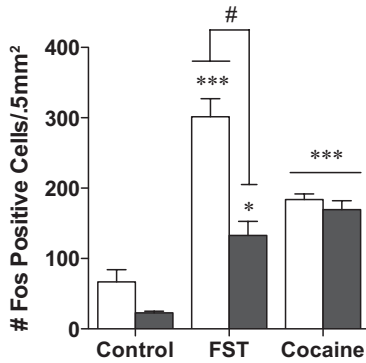

e NAc Core

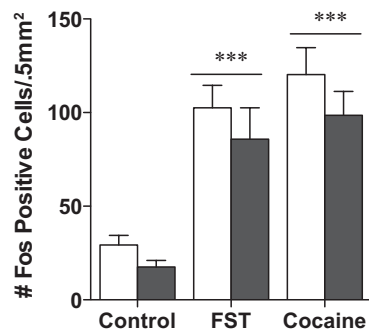

g Prelimbic Cortex

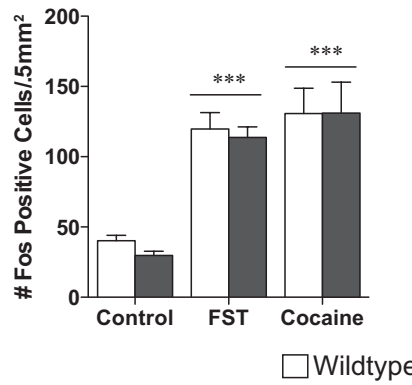

b dBNST

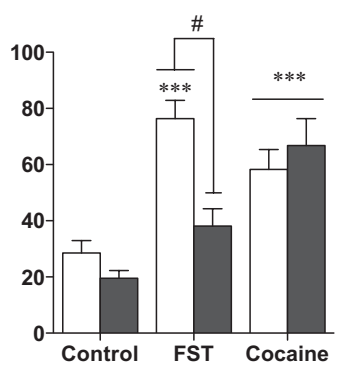

d NAc Shell

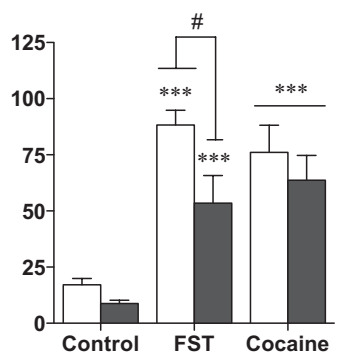

f Lateral Hypothalamus

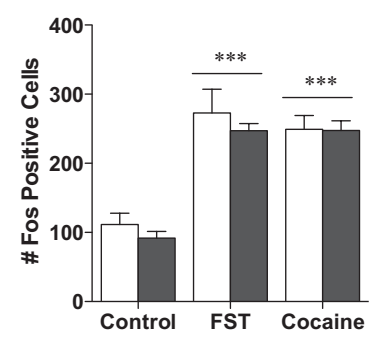

h Infralimbic Cortex

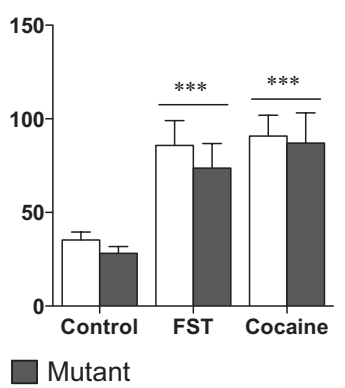

Figure 1. CREB mutant mice exhibit decreased Fos protein expression in response to stress but not to cocaine. Although wild-type mice exhibit an increase in Fos protein in the ventral $(\boldsymbol{a})$ and dorsal (b) BNST, lateral septum (c), and the nucleus accumbens shell $(\boldsymbol{d})$ in response to forced swim stress, CREB $\alpha \Delta$ mutant mice do not. This decreased stress response is not seen in the nucleus accumbens core $(\boldsymbol{e})$, lateral hypothalamus $(\boldsymbol{f})$, prelimbic cortex $(\boldsymbol{g})$, or infralimbic cortex $(\boldsymbol{h})$. No differences were seen between the genotypes in response to an acute cocaine injection $(\boldsymbol{a}-\boldsymbol{h}) .{ }^{*} p<0.05,{ }^{* *} p<0.01$, ${ }^{* * *} p<0.001$ compared with control; ${ }^{*} p<0.05$ pairwise comparison for wild-type versus mutant forced swim test (FST).

and preference score as the dependent variable. Behavior during the swim stress was compared between wild-type and CREB mutant mice using an unpaired $t$ test with genotype as the independent variable and total time spent immobile as the dependent variable. The number of single- or double-labeled cells in each brain region was determined for each animal. Group differences in Fos immunoreactivity or Fos/FG double-labeled cells were assessed using two-way ANOVAs within the stress group with drug treatment and genotype as the independent variables and number of cells as the dependent variable. Two-way ANOVAs were also performed within genotype to make comparisons between stress and control.

\section{Experiment III}

Subjects. A total of 38 wild-type F1 hybrid (129SvEvTac/C57BL/6NTac) mice were single housed with food and water available ad libitum. All animals (2-4 months of age) were housed in a temperature- and humidity-controlled animal care facility with a $12 \mathrm{~h}$ light/dark cycle (lights on a 7:00 A.M.). All procedures were approved by the University of Pennsylvania Animal Care and Use Committee.

Cannula placement surgeries. The stereotaxic surgeries were performed as described in Experiment I with the following exceptions. Guide cannula ( $9 \mathrm{~mm}, 24$ gauge) for microinjections were implanted bilaterally, dorsal to the BNST. Coordinates for the tip of the guide cannula relative to bregma, according to Franklin and Paxinos (2007), were $+0.5 \mathrm{~mm}$ anteroposterior, $\pm 0.9 \mathrm{~mm}$ mediolateral, and $-2.5 \mathrm{~mm}$ dorsoventral. Cannulae were cemented in place using Cerebond Skull Fixture Adhesive (Plastics One). Obturators ( $9 \mathrm{~mm}$, stainless steel 33 gauge wire; Small Parts) were inserted into the guide cannula to prevent occlusion. Lidocaine $\mathrm{HCl}$ and vehicle (PBS) microinjections were delivered using stainless steel 33 gauge microinjectors that extended $1.2 \mathrm{~mm}$ below the guide cannula (thus leading to direct administration into the BNST).

Conditioned place preference. After 7-10 d of recovery from the cannulae implantation surgery, mice underwent the cocaine conditioning paradigm as described for Experiment II with the following exceptions.

Stress-induced reinstatement test. Two to $3 \mathrm{~d}$ after the extinction test, animals underwent the stress-induced reinstatement test. Eight minutes before exposure to a $6 \mathrm{~min}$ forced swim stress, mice received microinjections of either PBS or 4\% lidocaine $\mathrm{HCl}$ dissolved in PBS. Bilateral infusions were performed simultaneously over a $120 \mathrm{~s}$ interval for a total volume of $0.4 \mu \mathrm{l} / \mathrm{side}$. Microinjectors were left in place for $60 \mathrm{~s}$ after the microinfusions to allow for the diffusion of the drug or vehicle away from the cannula tips before removal. After the swim stress exposure, animals were placed back in their home cage for $15 \mathrm{~min}$ before their preference test. During the 15 min preference test, the amount of time the animal spent on each side of the box was recorded. Transcardial perfusions were performed $25 \mathrm{~min}$ after the end of the reinstatement preference test.

Tissue collection, immunohistochemistry, and data analysis. Tissue collection, immunohistochemistry, and data analysis were as described for Experiment I.

Statistical analysis. The ability of cocaine to induce place preference behavior, the ability of extinction training to eliminate this preference, and the ability of swim stress to reinstate place preference was assessed using two-way ANOVA with test day (pretest vs posttest, extinction test, reinstatement test) and infusion (lidocaine vs vehicle) as the independent variables and preference score as the dependent variable. The number of Fos-positive cells in each brain region was determined for each animal. Group differences in Fos immunoreactivity between the vehicle- and lidocaine-treated animals were assessed using unpaired $t$ tests using infusion as the independent variable and number of cells as the dependent variable.

Anatomical specificity analysis. To determine the anatomical specificity of the lidocaine infusions into the BNST and ensure that the behavioral results were not attributable to actions within the ventricular system, we performed an additional control experiment. Animals were implanted with cannula in either the BNST (as described above) or in the lateral ventricle $(-0.6 \mathrm{~mm}$ anteroposterior, $\pm 0.12 \mathrm{~mm}$ mediolateral, $-1.2 \mathrm{~mm}$ dorsoventral; microinjector lowered to $-2.2 \mathrm{~mm}$ dorsoventral). After recovery from surgery, animals were given $0.4 \mu \mathrm{l}$ microinfusions of either lidocaine $\mathrm{HCl}(4 \%)$ or vehicle and placed back in their home cage for 8 min. All animals then underwent a $6 \mathrm{~min}$ swim stress during which swimming behavior was recorded and analyzed (Cleversys). The time spent immobile over the last 4 min of the swim was used as the behavioral output measure. 


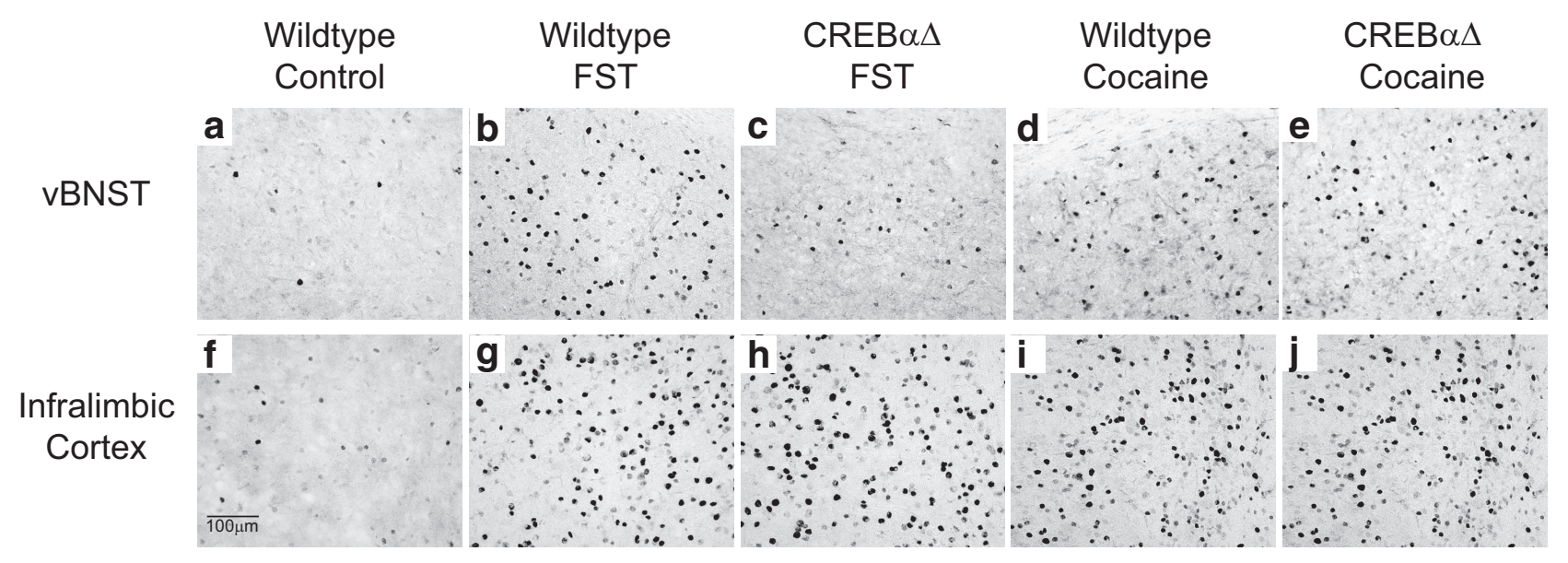

Figure 2. Fos immunoreactivity after swim stress and acute cocaine administration. Example photomicrographs demonstrating that wild-type mice exhibit an increase in Fos protein expression within the vBNST $(\boldsymbol{b}, \boldsymbol{d})$ and IL $(\boldsymbol{g}, \boldsymbol{i})$ after forced swim stress or acute cocaine administration. CREB $\alpha \Delta$ mutant mice do not show stress-induced increases in Fos protein expression within the vBNST $(\boldsymbol{c})$, whereas expression within the IL remains intact $(\boldsymbol{h})$. No differences are seen in the response to acute cocaine in CREB $\alpha \Delta$ mutant mice $(\boldsymbol{e}, \boldsymbol{j})$ FST, Forced swim test.

\section{Results}

\section{Experiment I}

CREB is necessary for stress-elicited Fos expression in specific forebrain regions

Quantification of Fos labeling revealed an increase in the number of Fos-immunoreactive profiles in wild-type mice within brain regions that have been implicated in stress responsivity and regions that have been implicated in addiction. These included the ventral (v) and dorsal (d) BNST, lateral septum (LS), NAc shell and core, lateral hypothalamus $(\mathrm{LH})$, prelimbic cortex $(\mathrm{PrL})$, and infralimbic cortex (IL) (Fig. 1; for representative photomicrographs, see Fig. 2). No changes in Fos immunoreactivity were seen in the amygdala or hippocampus after swim stress (data not shown).

Compared with wild-type mice, stress-induced Fos immunoreactivity was significantly blunted in $\mathrm{CREB} \alpha \Delta$ mutant mice within the ventral and dorsal BNST, LS, and NAc shell (Fig. 1) (interaction between stress and genotype: vBNST, $F_{(1,30)}=6.08$, $p=0.02$; dBNST, $F_{(1,30)}=7.86, p=0.009$; NAc shell, $F_{(1,30)}=$ $3.97, p=0.05$; LS, $\left.F_{(1,30)}=10.07, p=0.004\right)$. However, comparable stress-induced increases were seen in the NAc core, LH, PrL, and IL of wild-type and CREB $\alpha \Delta$ mutant mice (Figs. 1, 2) (main effect of stress: NAc core, $F_{(1,30)}=45.07, p<0.0001$; LH, $F_{(1,30)}=$ 57.54, $p<0.0001$; PrL, $F_{(1,30)}=109.0, p<0.0001$; IL, $F_{(1,30)}=$ 24.80, $p<0.0001)$. The lower number of Fos-immunoreactive neurons in $\mathrm{CREB} \alpha \Delta$ mutants could not be attributed to decreased activity during the swim stress because immobility was greater in wild-type littermates (mean \pm SEM time spent immobile: wild-type, $312 \pm 6 \mathrm{~s}$; mutant, $190 \pm 23 \mathrm{~s} ; t_{(12)}=4.44 ; p=$ 0.0008) (Fig. 3a), as shown previously (Conti et al., 2002).

Cocaine-elicited Fos expression is regionally similar to stress-induced expression but is not CREB dependent

Cocaine increased Fos immunoreactivity in the same forebrain regions that were activated by stress (Fig. 1; for representative photomicrographs, see Fig. 2). Although the magnitude of cocaine- or stress-induced Fos activation was similar in most brain regions, cocaine-exposed mice exhibited less activation compared with stressed mice in the LS (Bonferroni's post hoc test, $p<0.001)$. In response to cocaine, $\mathrm{CREB} \alpha \Delta$ mutant mice exhibited the same magnitude of Fos immunoreactivity as wild-type mice (Fig. 1) (main effect of drug: vBNST, $F_{(1,32)}=32.66, p<$ 0.0001 ; dBNST, $F_{(1,32)}=39.92, p<0.0001$; NAc shell, $F_{(1,32)}=$
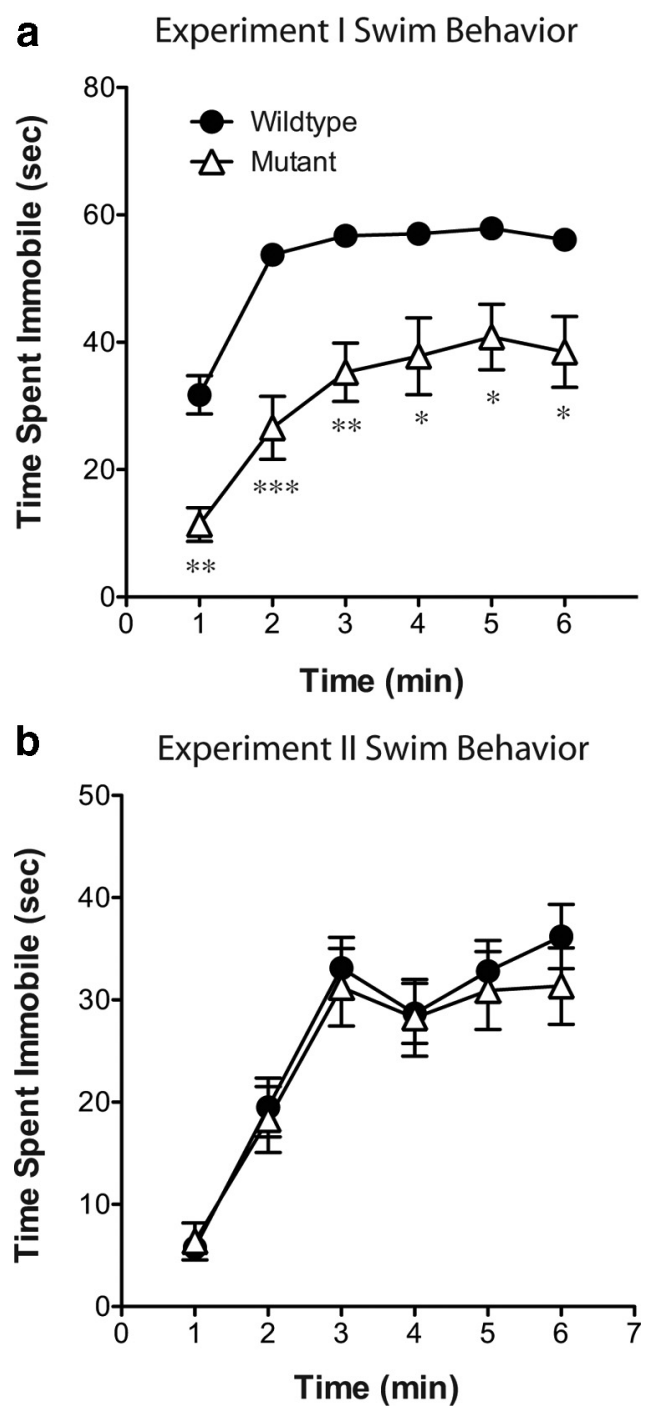

Figure 3. Naive CREB mutant mice exhibit a decrease in immobility during swim stress compared with wild-type littermates; however, conditioned place preference-experienced animals do not. Throughout the forced swim test in experiment I (a), mutantmice exhibited lowerlevels of immobility than their wild-type littermates. However, in experiment II $(\boldsymbol{b})$, no differences were seen between the genotypes. ${ }^{*} p<0.05,{ }^{* *} p<0.01,{ }^{* * *} p<0.001$ compared with wild type. 


\section{Fluorogold Placements}
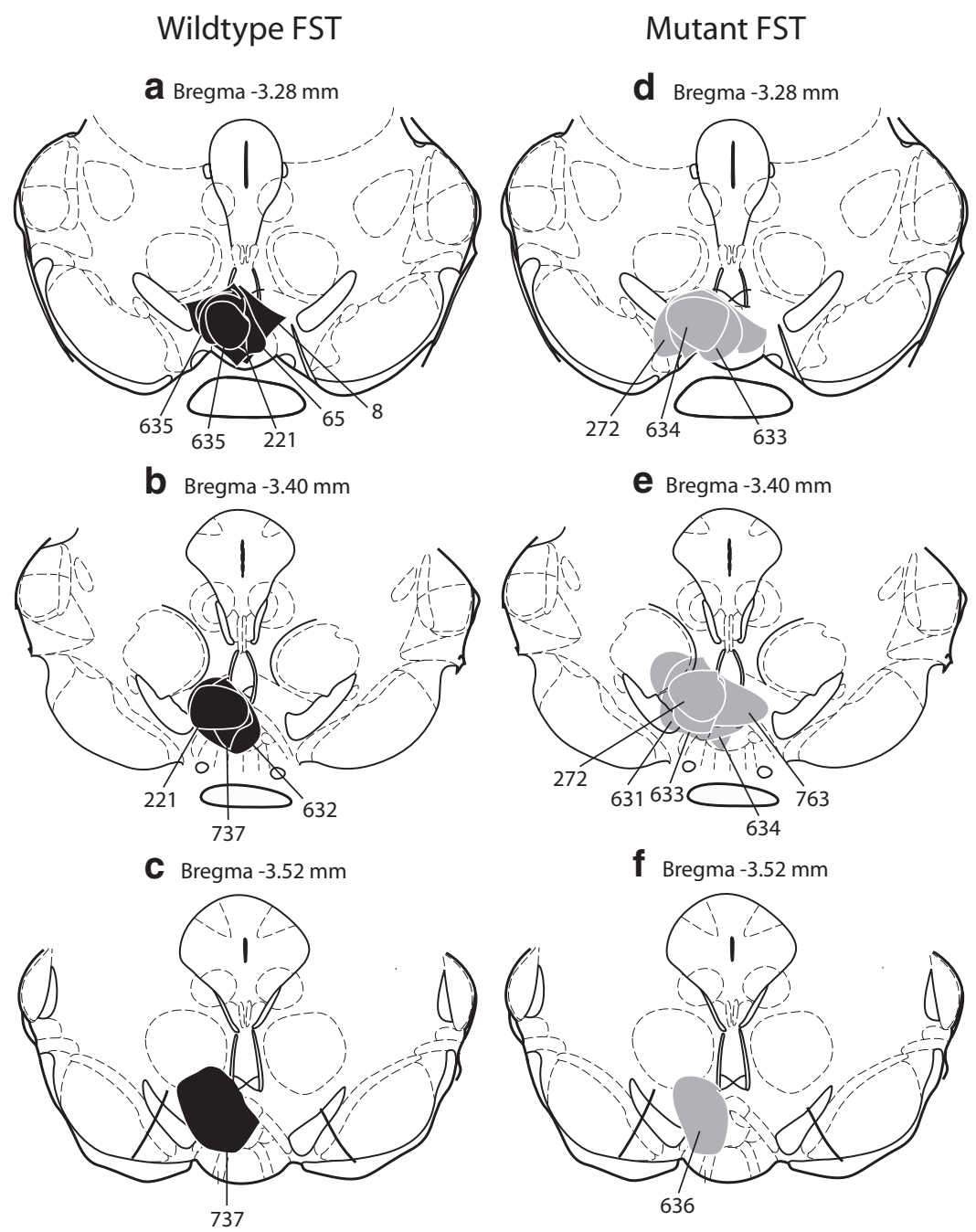

Figure 4. Animals with Fluorogold injections that filled the VTA unilaterally were included in double-labeled analysis. Schematic representation of injection sites from wild-type $(\boldsymbol{a}-\boldsymbol{c})$ and mutant $(\boldsymbol{d}-\boldsymbol{f})$ mice that were exposed to the forced swim test (FST). The injection sites and immediate spread of FG for individual animals are indicated by black (WT) or gray (mutant) circles and corresponding animal numbers. Cocaine and control injection sites were comparable.

37.44, $p<0.0001$; LS, $F_{(1,32)}=106.3, p<0.0001$; NAc core, $F_{(1,32)}=53.75, p<0.0001 ; \mathrm{LH}, F_{(1,32)}=91.03, p<0.0001 ; \operatorname{PrL}$, $F_{(1,32)}=40.14, p<0.0001 ;$ IL, $\left.F_{(1,32)}=27.92, p<0.0001\right)$.

Stress- and cocaine-induced Fos expression in VTA afferents: dependence on CREB

To elucidate circuits engaged after stress or cocaine administration, we used a functional anatomical approach that combined identification of cells expressing Fos with the retrograde tracer FG. In 17 of 25 wild-type and 19 of $25 \mathrm{CREB} \alpha \Delta$ mutant mice, the FG injection included all of the VTA unilaterally and spread into the contralateral side (Fig. 4). Because the extent and location of FG injections cannot be identical in every animal, only cases with relatively large injections that filled the VTA unilaterally were used in an attempt to minimize this limitation. In addition, the number of FG-positive cells were quantified in sections adjacent to those analyzed for the double labeling. The number of retrogradely labeled cells was comparable in sections from CREB $\alpha \Delta$ mutant mice and wild-type control mice (mean \pm SEM: wildtype LH, $102.78 \pm 12.98$; mutant LH, $109.64 \pm 11.08$; wild-type vBNST, $72.63 \pm 14.65$; mutant vBNST, $70.78 \pm 7.82)$, indicating that neuronal projection patterns are similar in mutant mice and that the extent of tracer injected was also comparable. Retrogradely labeled neurons were observed in regions previously described as VTA afferents in the rat (Geisler and Zahm, 2005), including the prefrontal cortex, NAc shell, medial preoptic area, BNST, $\mathrm{LH}$, and the lateral habenula. Doublelabeled analyses were conducted within the IL, BNST, and LH because these regions exhibited consistent retrograde labeling within all animals with accurate FG injections. Interestingly, no retrograde labeling was seen within the medial or lateral septum, indicating a potential difference between the connectivity of the mouse and rat.

In wild-type mice, swim stress increased Fos expression in neurons in the vBNST and IL that project to the VTA (for representative photomicrographs, Figs. $5 a, b, 6)$. However, in the dBNST and the $\mathrm{LH}$, there was no significant increase in Fos expression in those neurons that project to the VTA (Fig. $5 c, d$ ), despite the overall increase in Fos immunoreactivity seen in this brain region after stress (Fig. $1 b, f)$. These data demonstrate that the subset of neurons that are activated by stress may project to regions other than the VTA or comprise primarily interneurons.

Consistent with reduced stress-elicited Fos expression in the vBNST in CREB $\alpha \Delta$ mutant mice, Fos expression in VTA afferents in this region was also decreased in $\mathrm{CREB} \alpha \Delta$ mutant mice, suggesting that activation of VTA afferents in the vBNST are particularly sensitive to the loss of CREB (Figs. 1 $a, 5 a$ ) (interaction between stress and genotype, $F_{(1,19)}=7.58, p=$ $0.01)$. In the IL, the overall number of Fosexpressing neurons after swim stress was unaffected by genotype; however, the specific population of neurons in this region that project to the VTA was greatly reduced in CREB $\alpha \Delta$ mutant mice (Fig. $5 b$ ) (interaction between stress and genotype, $\left.F_{(1,19)}=10.16, p=0.006\right)$. In contrast to stress, cocaine-elicited Fos activation of VTA afferents was not dependent on CREB and was of a similar magnitude in wild-type and CREB $\alpha \Delta$ mutant mice (Fig. 5) (main effect of drug: vBNST, $F_{(1,21)}=19.80, p=0.0003$; dBNST, $F_{(1,21)}=$ $19.24, p=0.001$; LH, $F_{(1,21)}=15.25, p=0.001$; IL, $F_{(1,21)}=$ 20.29, $p=0.001$ ).

\section{Experiment II}

Stress-elicited Fos expression in certain forebrain regions is dependent on CREB but independent of cocaine CPP

In mice that underwent $\mathrm{CPP}$ and extinction (Fig. 7) but not reexposure to the conditioning environment, swim stress induced similar patterns of Fos expression as seen in naive mice (Fig. 8). No changes in Fos immunoreactivity were seen in the amygdala or hippocampus after swim stress (data not shown). Stressinduced Fos immunoreactivity was significantly blunted in $\mathrm{CREB} \alpha \Delta$ mutant mice within the ventral and dorsal BNST, LS, 
and NAc shell, and this was independent of saline or cocaine conditioning (Fig. 6) (main effect of genotype: vBNST, $F_{(1,38)}=$ 10.76, $p=0.002$; dBNST, $F_{(1,38)}=4.23, p=0.047$; NAc shell, $F_{(1,38)}=4.78, p=0.036$; LS, $\left.F_{(1,38)}=8.73, p=0.005\right)$. Comparable stress-induced increases were seen in the NAc core, LH, PrL, and IL regardless of genotype (Fig. 8). Although no interactions were present between genotype and drug pretreatment, a decrease in stress-induced Fos expression in the ventral and dorsal BNST was present in both genotypes after cocaine conditioning (Fig 8) (main effect of drug: vBNST, $F_{(1,38)}=10.14, p=0.003$; dBNST, $F_{(1,38)}=$ $8.29, p=0.007)$. Differences in Fos expression could not be attributed to different behaviors during the swim stress because the magnitude of immobility during the stress was identical in wild-type and $\mathrm{CREB} \alpha \Delta$ mutant mice (mean \pm SEM time spent immobile: wildtype, $156 \pm 13 \mathrm{~s}$; mutant, $146 \pm 17 \mathrm{~s} ; t_{(40)}=0.45 ; p=0.65$ ) (Fig. 3 ).

Stress-induced Fos expression in VTA afferents is dependent on $C R E B$ but independent of CPP drug treatment

In 28 wild-type and $26 \mathrm{CREB} \alpha \Delta$ mutant mice, the FG injection included all of the VTA unilaterally and spread into the contralateral side. In wild-type mice, swim stress given after extinction increased Fos expression in VTA afferents in the ventral BNST and IL, similar to the increase seen in naive mice. Additionally, exposure to swim stress in CPP-experienced wild-type mice increased Fos in VTA afferents in the dorsal BNST (Fig. 9b). This effect was apparent in both saline- and cocaine-experienced mice and suggests that animals that have undergone conditioning exhibit differential activation patterns in response to stress exposure compared with naive mice. Although there was a trend for stress to increase Fos expression in the $\mathrm{LH}$ of naive mice, this increase only reaches significance in conditioned mice (Fig. 9c).

Consistent with reduced stress-elicited Fos expression in the ventral and dorsal BNST in CREB $\alpha \Delta$ mutant mice, Fos expression in VTA afferents in these regions was also decreased in $\mathrm{CREB} \alpha \Delta$ mutant mice, suggesting again that the loss of CREB particularly affects VTA afferents in this region (Figs. $6 a, b, 9 a, b)$ (main effect of genotype: vBNST, $F_{(1,23)}=21.47, p=$ 0.0001 ; dBNST, $\left.F_{(1,23)}=9.67, p=0.006\right)$. Interestingly, although the overall number of Fos-expressing neurons in the IL and $\mathrm{LH}$ after swim stress was unaffected by genotype, the population of neurons in this region that projects to the VTA was greatly affected by genotype (Fig. 9). Thus, the number of VTA afferents in the IL and LH was substantially less in CREB $\alpha \Delta$ mutant mice, indicating a requirement for CREB in stress-elicited neuronal activation in these specific neuronal populations (Figs. $8 c, d, 9 c, d$ ) (main effect of genotype: LH, $F_{(1,23)}=11.38, p=0.003 ; \mathrm{IL}, F_{(1,23)}=11.81$, $p=0.002)$. Similar patterns of Fos expression were seen in saline- and cocaine-experienced mice in all brain regions examined, suggesting that stress-induced activation was not modulated by drug experience.

\section{Experiment III}

Injection of lidocaine into the BNST decreases swim-stress-induced reinstatement

Of all the brain regions examined after swim stress, the BNST exhibited the most marked decrease in activity within both the

\section{a VBNST}

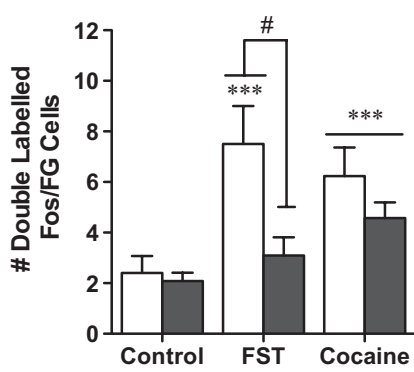

\section{C dBNST}

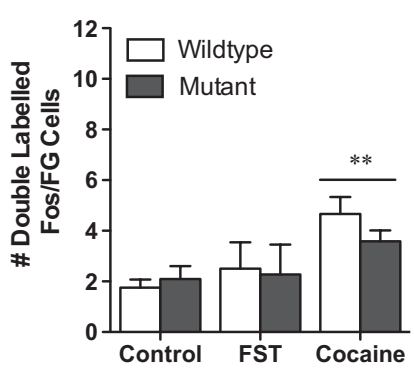

d Lateral Hypothalamus

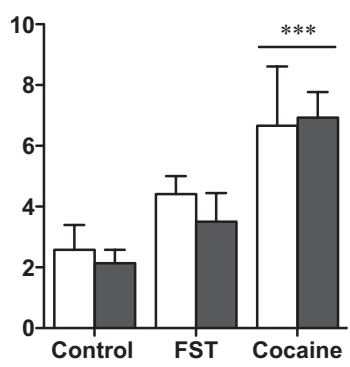

Figure 5. CREB mutant mice exhibit a decrease in stress-activated cells that project to the VTA. Although wild-type mice exhibit an increase in Fos-activated cells that project to the ventral tegmental area (doubled-labeled Fos/FG cells) in the ventral BNST (a) and the infralimbic cortex (b), CREB $\alpha \Delta$ mutant mice do not. Although no differences were seen between the genotypes in response to acute cocaine, there was an increase in double-labeled cells in two regions that did not show stress-induced alterations, the dorsal BNST (c) and the lateral hypothalamus (d). ${ }^{* *} p<0.01,{ }^{* * *} p<0.001$ compared with control; ${ }^{*} p<0.05$ pairwise comparison for wild-type versus mutant forced swim test (FST).

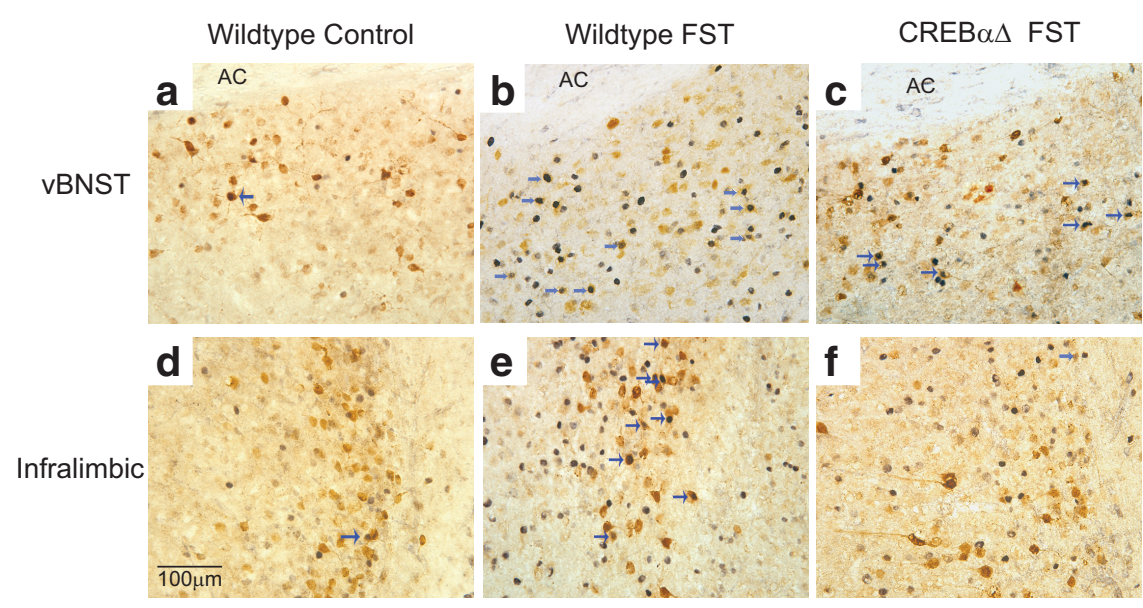

Figure 6. Double labeling of Fos and Fluorogold immunoreactivity after forced swim stress. Example photomicrographs demonstrating the increase in Fos protein expression within VTA afferents in the VBNST $(\boldsymbol{b})$ and IL $(\boldsymbol{e})$ of wild-type mice after forced swim stress (FST). These specific increases in Fos immunoreactivity within cells that project to the VTA was not seen within CREB $\alpha \Delta$ mutant mice $(\boldsymbol{c}, \boldsymbol{f})$. AC, Anterior commissure.

overall cell population and projections to the VTA in CREBdeficient mice. Furthermore, stress-induced reinstatement was impaired by a global CREB deficiency that included the BNST. Therefore, to determine whether activation of the BNST is necessary for stress-induced reinstatement of conditioned reward in mice, we examined the effect of lidocaine inactivation of the BNST on the reinstatement test. Before any inactivation, both the vehicle and lidocaine groups exhibited similar levels of preference for the drug-paired side on test day (Fig. 10) $\left(F_{(1,16)}=65.59, p<\right.$ 


\section{Conditioned Place Preference Behavior}

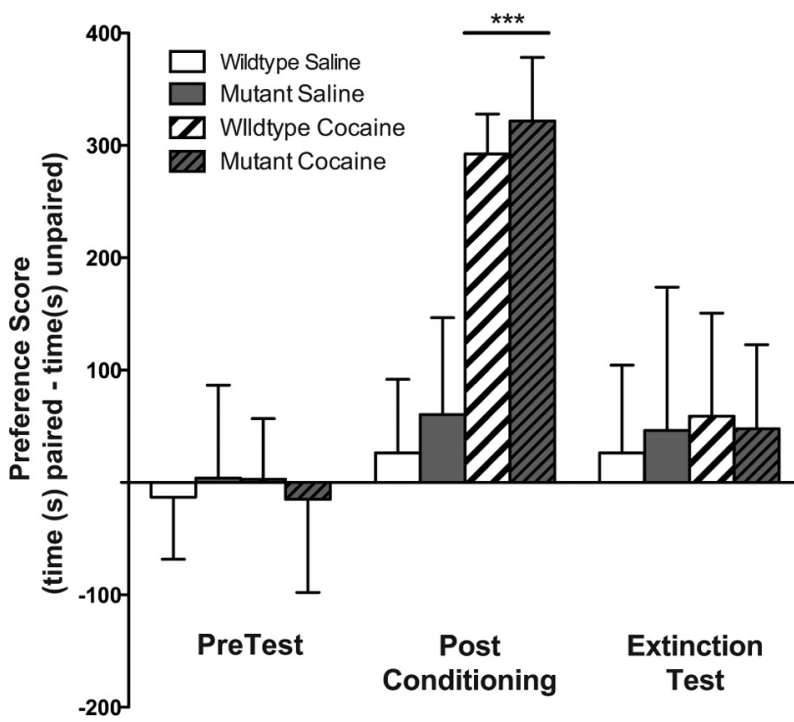

Figure 7. Cocaine-induced conditioned place preference behavior in both mutant and wildtype mice and extinction training eliminated this preference. Both wild-type and mutant mice paired with cocaine showed a significant place preference to the cocaine-paired side on test day (drug, $F_{(1,72)}=43.12, p<0.0001$ ). After extinction training, this preference was no longer present. ${ }^{* *} p<0.001$ compared to PreTest.

0.0001) and no preference after the extinction (Fig. 10). In vehicle-treated mice, the swim stress increased the preference for the drug-paired side on reinstatement day. However, the lidocaine-treated animals did not exhibit a preference for the drug-paired side after stress exposure (Fig. 10) (vehicle-treated vs lidocaine-treated, $\left.t_{(16)}=2.61, p=0.019\right)$. No differences were seen between vehicle and lidocaine infusion in saline-conditioned mice (data not shown). To control for potential nonspecific effects of lidocaine on the ventricular system, in a separate cohort of animals, we injected the drug directly into the lateral ventricle. Although lidocaine inactivation of the BNST led to a significant decrease in the time spent immobile in the forced swim test $\left(t_{(16)}=2.43 ; p=0.029\right)$ (Fig. 11), lidocaine infusion into the lateral ventricle has no effect on swim stress behavior.

Injection of lidocaine into the BNST decreases Fos activation after swim-stress-induced reinstatement

Consistent with the lack of stress-induced reinstatement of CPP in the lidocaine-treated mice, reinstatement-induced Fos activation was also blunted in these animals. Importantly, Fos was substantially reduced in the VTA, consistent with inactivation of the BNST population of VTA afferents (Fig. 12a) $\left(t_{(15)}=2.15 ; p=\right.$ $0.049)$. Stress-induced Fos activation was also blunted in the NAc core, which is downstream of the BNST (Fig. 12c) $\left(t_{(15)}=2.36\right.$; $p=0.031$ ). Additionally, Fos was blunted in the CeA (Fig. 12b) $\left(t_{(15)}=2.65 ; p<0.05\right)$, which is considered upstream from the BNST although there are reciprocal connections between the two structures. Similar patterns of Fos expression were seen in vehicle- and lidocaine-treated mice within the NAc shell, prefrontal cortex (both prelimbic and infralimbic subregions), and the lateral hypothalamus (Fig. 12d-g). No differences in Fos expression were seen between the vehicle and lidocaine groups in saline-conditioned mice, indicating that lidocaine alone did not affect Fos expression (data not shown). a vBNST

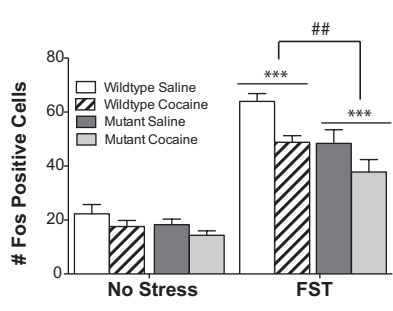

C Lateral Septum
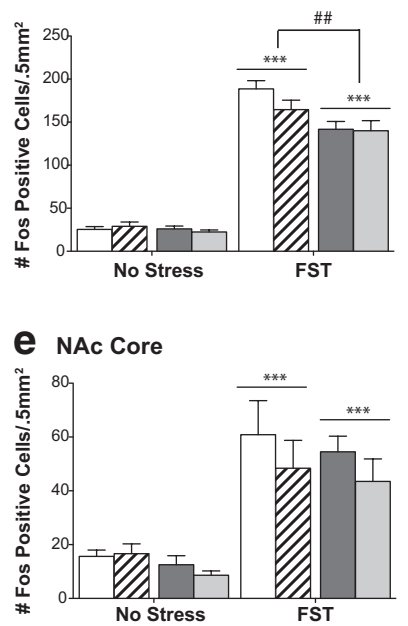

g Prelimbic Cortex

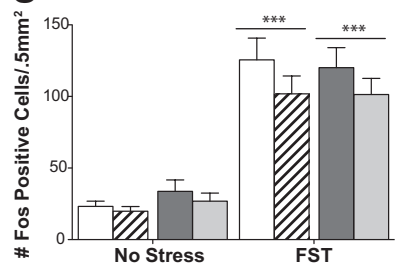

b dBNST

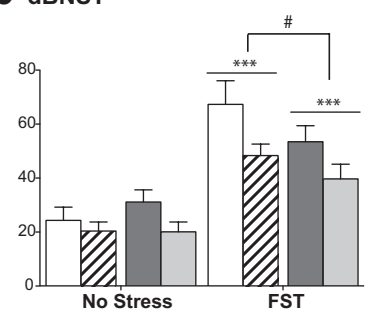

d NAc Shell

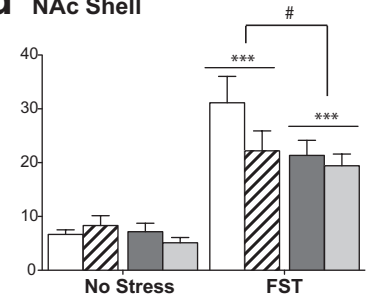

f Lateral Hypothalamus

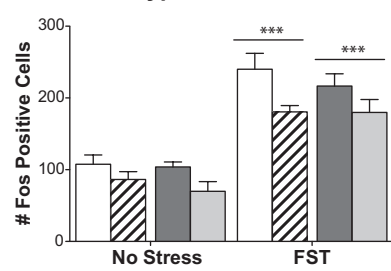

h Infralimbic Cortex

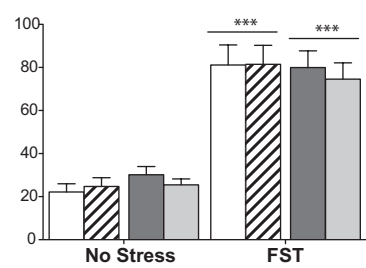

Figure 8. CREB mutant mice exhibit blunted stress-induced Fos protein expression independent of previous drug conditioning. Although wild-type mice exhibit an increase in Fos protein in the ventral ( $\boldsymbol{a}$ ) and dorsal ( $\boldsymbol{b}$ ) BNST, lateral septum ( $\boldsymbol{c}$, and the nucleus accumbens shell (d) in response to forced swim stress, CREB $\alpha \Delta$ mutant mice do not. Although no interactions were present between genotype and drug pretreatment, a decrease in stress-induced Fos expression in the ventral and dorsal BNST was present in both genotypes after cocaine conditioning. Comparable stress-induced Fos expression was seen in both genotypes in the nucleus accumbens core $(\boldsymbol{e})$, lateral hypothalamus $(\boldsymbol{f})$, prelimbic cortex $(\boldsymbol{g})$, or infralimbic cortex $(\boldsymbol{h}) .{ }^{*} p<0.05$, ${ }^{* *} p<0.01$ compared with No Stress condition, \#p $<0.05$, \#\#p $<0.01$ genotype comparison of wild type versus mutant within the FST groups.

\section{Discussion}

The objective of the present studies was to identify the circuitry underlying stress-induced reinstatement of CPP behavior. Our previous demonstration that CREB is required for this behavior (Kreibich and Blendy, 2004) allowed us to use functional neuroanatomy in the specific genetic model $\operatorname{CREB} \alpha \Delta$ mutant mice to pinpoint the neuronal populations that are integral to this effect. We identified VTA-projecting neurons that were selectively activated in wild-type, but not mutant, mice by a stressor that produces reinstatement. These neurons were localized in the lateral hypothalamus, infralimbic cortex, and the BNST, an area that has been implicated in reinstatement through involvement of the stress-related neuropeptide CRF. The importance of the BNST was further underscored by the finding that inactivation of this region prevented stress-induced CPP reinstatement and attenu- 
ated neuronal activation of VTA neurons and neurons downstream from the VTA. Together with the genetic differences in stress-induced reinstatement behavior and neuronal activation, these findings emphasize the critical role of CREB in afferents to the VTA and in particular the importance of the BNST in stressinduced reinstatement.

\section{Common activation of neural circuits by stress and cocaine}

The current study is unique in that it provides us with a picture of neuronal activation patterns elicited by stress or cocaine as they relate to reinstatement. Interestingly, acute stress and acute cocaine exposure produced nearly identical patterns of Fos activation in wild-type animals. However, acute stress exposure led to an increase in Fos activation within brain regions typically thought to be involved in mediating the rewarding properties of drugs, such as the NAc core (Kalivas and McFarland, 2003). Conversely, acute cocaine administration led to an increase in Fos protein expression in brain regions typically thought to be involved in stress reactivity, such as the lateral septum and BNST. These findings suggest that there is considerable overlap between the circuits involved in addiction and stress. It is possible that other cells may be activated that are not detected by Fos and equally possible that stress and cocaine activate different cell populations within these brain regions. It would be of interest to determine whether the same neuronal populations within specific brain regions are activated by both cocaine and stress. However, to fully characterize these neurons, we would need to look beyond neurochemical identity and characterize unique molecular or genomic fingerprints of each population to determine whether they are the same cells.

\section{Activation of VTA afferents by stress and cocaine}

Although patterns of Fos elicited by stress and cocaine are informative, alone they do not reveal how these stimuli engage reward circuitry. The VTA is a potential point of intersection between stress and reward circuits (Roberts and Koob, 1982; Stewart, 1984). The stress neuropeptide CRF works within the VTA to promote reinstatement behavior (Wang et al., 2007). Therefore, Fos expression patterns within the specific cell populations that project to the VTA were characterized. Retrogradely labeled neurons were observed in regions previously described as VTA afferents in the rat (Geisler and Zahm, 2005), including the prefrontal cortex, NAc shell, medial preoptic area, BNST, LH, and the lateral habenula. Both cocaine- and stress-exposed mice displayed labeling of VTA afferents within the vBNST and IL. This implicates these two regions as sites at which stress engages reward circuitry, at least through convergence on the VTA.

\section{Importance of CREB in the effects of stress, but not cocaine, on activating reward circuitry}

The transcription factor CREB is expressed in all cells within the brain and is critically involved in transducing cellular signaling to alterations in gene expression. By activating gene expression,

\section{a vBNST}

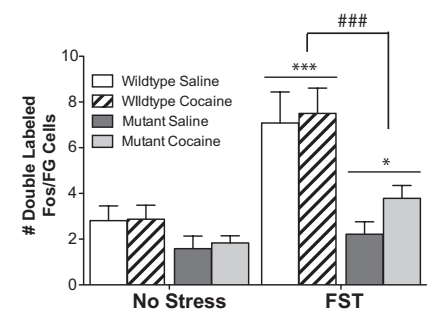

C Lateral Hypothalamus

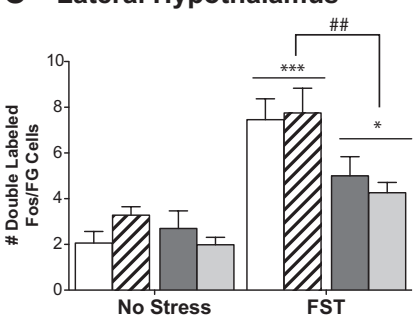

b dBNST

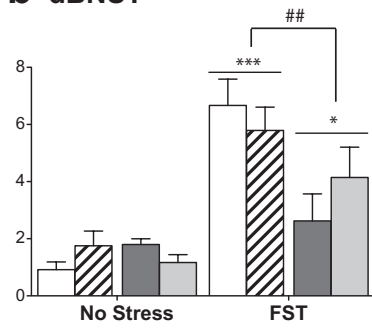

d Infralimbic Cortex

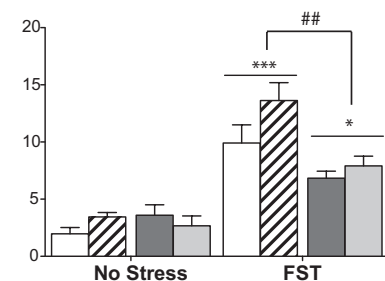

Figure 9. CREB mutant mice exhibit a decrease in stress-activated cells that project to the VTA independent of previous drug conditioning. Although wild-type mice exhibit an increase in Fos-activated cells that project to the ventral tegmental area (doubled-labeled Fos/FG cells) in the ventral $(\boldsymbol{a})$ and dorsal $(\boldsymbol{b})$ BNST, lateral hypothalamus $(\boldsymbol{c})$, and the infralimbic cortex (d), CREB $\alpha \Delta$ mutant mice do not. No differences in Fos-activated cells that project to the VTA were seen as a result of drug treatment during CPP. ${ }^{*} p<0.05,{ }^{* * *} p<0.001$ compared with No Stress condition; \#\#p $<0.01$, \#\#\#p $<0.001$ genotype comparison of wild type versus mutant within the FST groups.

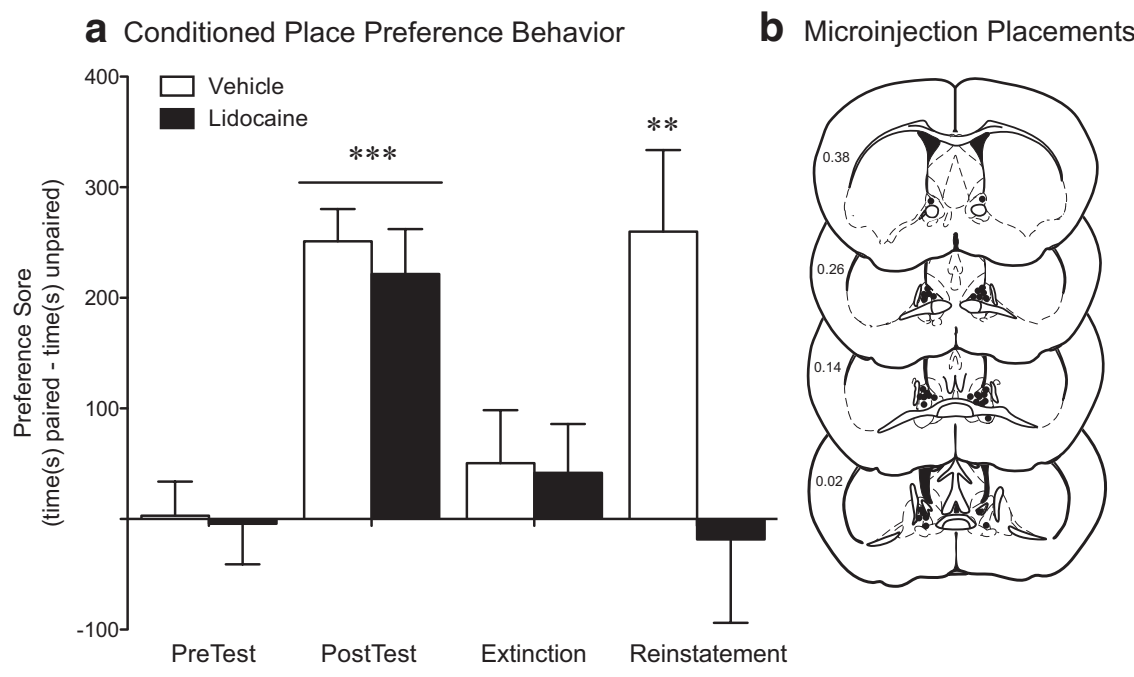

Figure 10. Stress-induced reinstatement requires BNST activation. $\boldsymbol{a}$, Vehicle- and lidocaine-treated mice exhibit similar levels of preference for the cocaine-paired side on the posttest day compared with their preferences before conditioning and similar levels of extinction. However, on reinstatement test day, only vehicle-treated animals exhibit a significant preference for the drug-paired side. ${ }^{* *} p<0.01$, extinction versus reinstatement; ${ }^{* * *} p<0.001$, posttest versus pretest. $\boldsymbol{b}$, Microinjector placements within the BNST for all cocaine-conditioned animals.
CREB is able to modulate levels of neuronal proteins and have an enduring effect on the function of neuronal circuits. These studies demonstrate the necessity of CREB in stress-induced, but not cocaine-induced, activation of specific neuronal populations in cocaine-conditioned and drug-naive animals. This corresponds to the requirement for CREB in stress-induced, but not cocaineinduced, reinstatement behavior (Kreibich and Blendy, 2004). Fos gene expression can be dependent on CREB activation (Sheng and Greenberg, 1990); therefore, it is important to note 
Time Immobile Last $4 \mathrm{~min}$

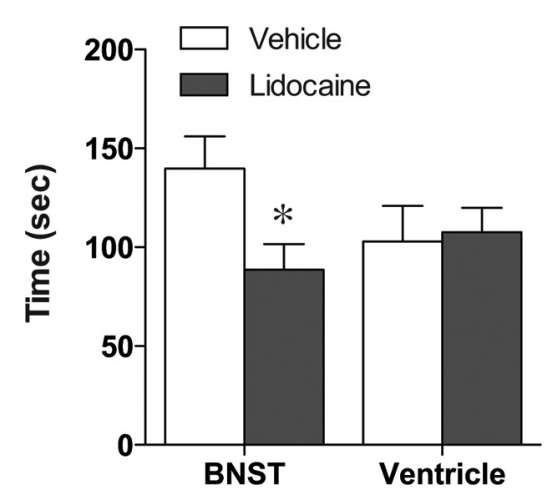

Figure 11. Inactivation of the BNST increases swimming in response to a forced swim stress. When lidocaine was infused into the BNST, mice exhibited a decrease in the time spent immobile during the last 4 min of a 6 min swim stress. No changes were seen when lidocaine was infused into the lateral ventricle. ${ }^{*} p<0.05$, lidocaine versus vehicle.

that Fos activation patterns in response to stress remain intact within the NAc core, $\mathrm{LH}$, and PrL. This suggests that the changes seen in the BNST, NAc shell, and LS do not represent a global inability of stress to induce Fos gene expression in CREB $\alpha \Delta$ mice.

\section{Impact of conditioning and CREB on neuronal activation in response to stress}

In the present studies, some neuronal populations, such as VTA afferents in vBNST and infralimbic cortex, exhibit increased activity after stress regardless of an animal's previous experience (naive or exposed to CPP), suggesting a hardwiring of some stress circuits that converge on the reward pathway. However, other regions in limbic circuitry exhibit a differential response depending on experience. For example, stress significantly activates VTA afferents in the lateral hypothalamus and dBNST only in animals that have undergone conditioning. Surprisingly, this was not dependent on cocaine exposure, because mice conditioned to saline in this paradigm show equally robust increases in double-labeled cells. CREB-deficient mice, which do not exhibit reinstatement behavior after stress, exhibited blunted Fos expression compared with wild-type mice in VTA afferents, suggesting these as potential neural substrates underlying stress-induced reinstatement.

\section{CREB-dependent brain regions are implicated in stress-induced reinstatement}

It is noteworthy that, in the IL, CREB was necessary for stresselicited Fos activation selectively in VTA afferents. The infralimbic cortex has been implicated in extinction, and lesions of the IL have been shown to facilitate reinstatement of extinguished responding (Coutureau and Killcross, 2003; Rhodes and Killcross, 2004; Rhodes and Killcross, 2007; Peters et al., 2008). In addition, a recent paper by Peters et al. (2008) demonstrated that activation of the IL after a cocaine-priming injection blocked reinstatement. However, correlations have been seen between IL Fos induction and contextual reinstatement of cocaine seeking (Hamlin et al., 2008), suggesting that IL activation may not always lead to decreased drug seeking. It is important to note that the above studies examined all IL neurons and not the particular subset that projects to the VTA. When examining Fos activation within the entire IL cell population, we do not see differences between $\operatorname{CREB} \alpha \Delta$ and wild-type mice, suggesting that there is something unique about the cell population that projects to the VTA. Dis-

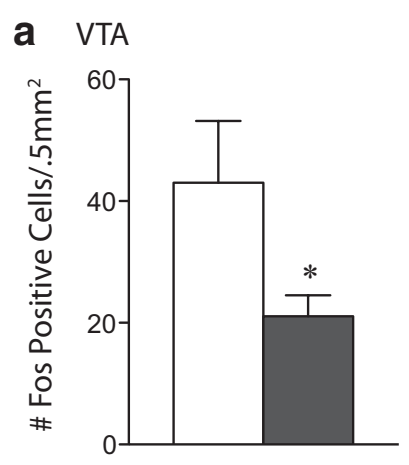

b $C e A$
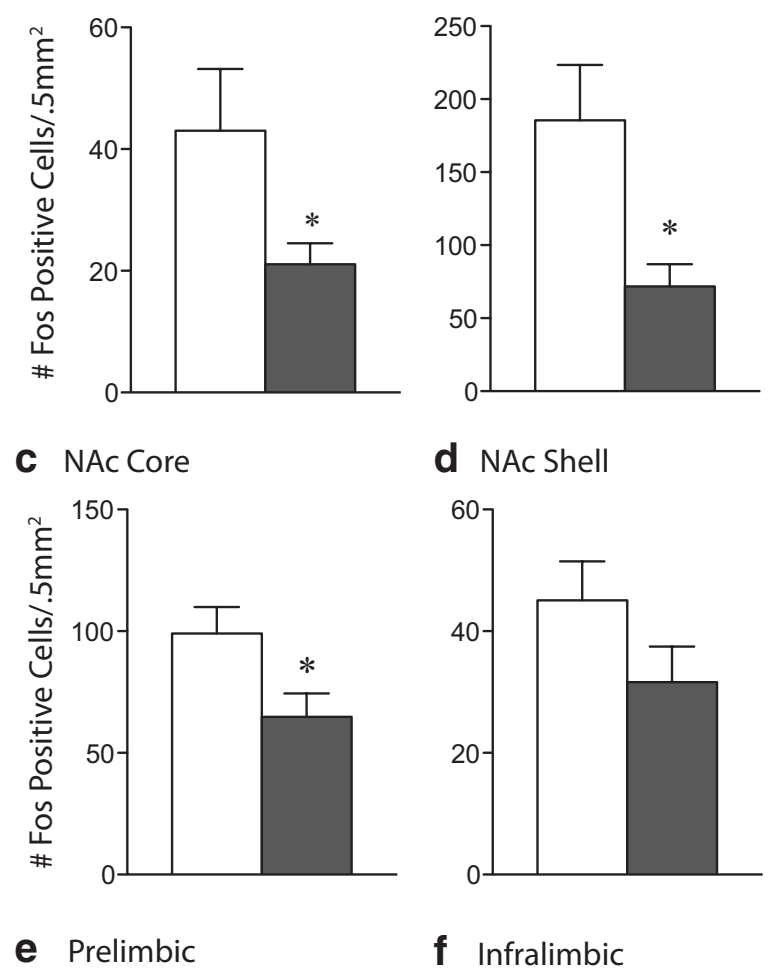

d NAc Shell
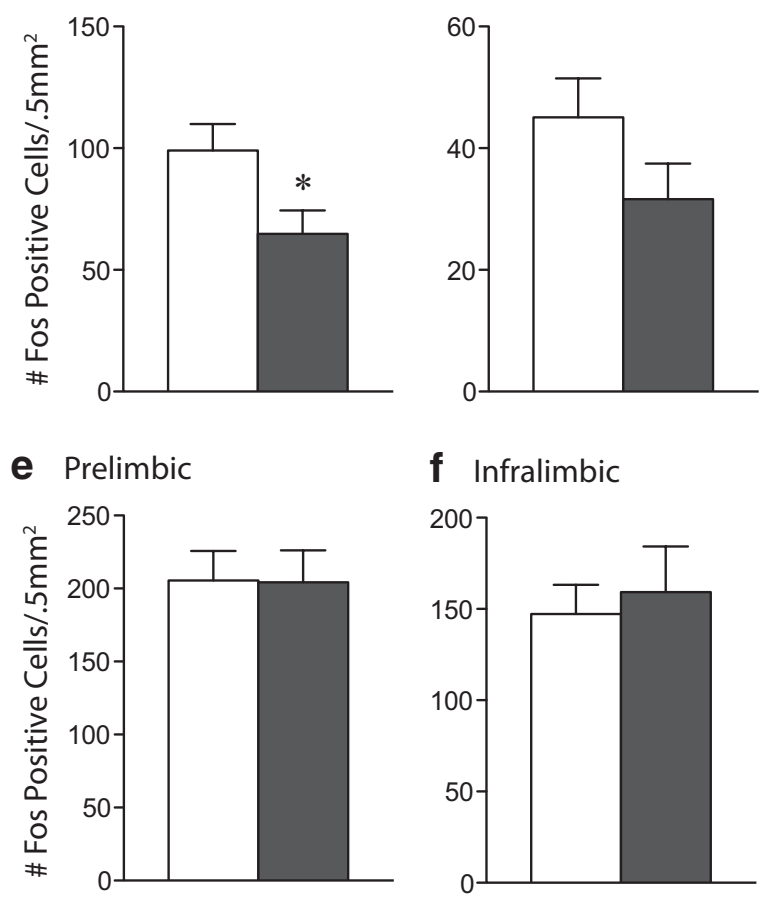

f Infralimbic

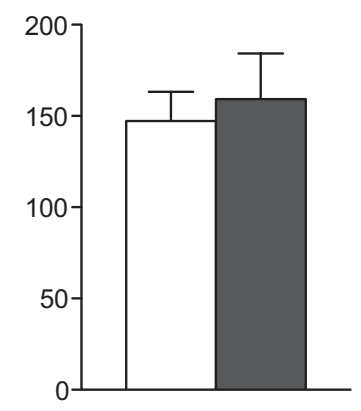

g Lateral Hypothalamus

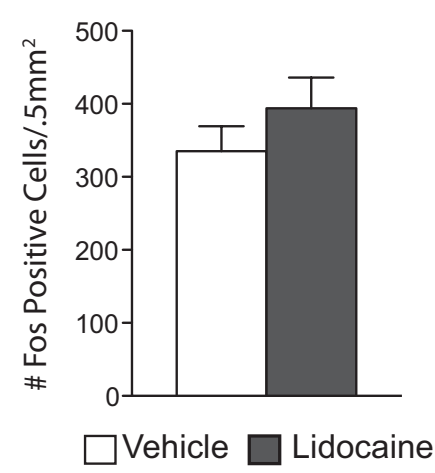

Figure 12. Inactivation of the BNST blunts activation of stress-induced reinstatement circuitry. Lidocaine-treated mice exhibit a blunted response to stress-induced reinstatement as indicated by a decrease in the number of Fos-positive cells within the VTA ( $\boldsymbol{a})$, CeA (b), and NAc core $(\boldsymbol{c})$. No differences were seen between the groups within the NAc shell $(\boldsymbol{d})$, prelimbic $(\boldsymbol{e})$ or infralimbic $(\boldsymbol{f})$ cortices, or the lateral hypothalamus $(\boldsymbol{g}) .{ }^{*} p<0.05$, vehicle versus lidocaine.

tinct cell populations within the IL have already been implicated in drug-seeking behavior (Zavala et al., 2008). Additional work on the effects of stress on the IL in $\mathrm{CREB} \alpha \Delta$ mutant mice may reveal a more complex role for this structure in mediating reinstatement. 
The lateral hypothalamus has long been implicated in reward processing (Olds, 1962, 1979; Corrigall, 1987). Recent work focusing on the lateral hypothalamic neuropeptide orexin has demonstrated that projections from the lateral hypothalamus to the ventral tegmental area mediate reinstatement of drug seeking. Specifically, activation of hypothalamic orexin neurons or direct infusion of orexin agonists into the VTA leads to reinstatement of drug-seeking behavior (Harris et al., 2005). Furthermore, orexin antagonists block stress-induced reinstatement of cocaine seeking (Boutrel et al., 2005). Therefore, stress may be unable to induce orexin signaling in $\mathrm{CREB} \alpha \Delta$ mice, contributing to their resistance to stress-induced reinstatement of cocaine-conditioned reward.

A role for both the dorsal and ventral BNST in stress-elicited CPP reinstatement is consistent with findings in the literature. For example, inactivation of the vBNST, as well as disruptions of either CRF or norepinephrine signaling within the vBNST, blocks the ability of stress to reinstate drug seeking (Erb and Stewart, 1999; Erb et al., 2001; Wang et al., 2001; Leri et al., 2002; Wang et al., 2006). Additionally, stress exposure in animals with a history of heroin self-administration leads to an increase in CRF mRNA within the dBNST (Shalev et al., 2001). Furthermore, direct infusions of CRF into the BNST lead to reinstatement of selfadministration behavior (Erb and Stewart, 1999). Together, these findings suggest that CREB in the BNST may be critically involved in either CRF or norepinephrine signaling, and disruption of this signaling prevents stress from reinstating drug seeking in the $\operatorname{CREB} \alpha \Delta$ mutant mice.

\section{Specific role for the BNST in reinstatement and the activation of reinstatement circuitry}

Stress-induced activation of the BNST was consistently dependent on CREB in both naive and cocaine-conditioned mice; therefore, we examined the functional role of the BNST in the circuit. Lidocaine inactivation of the BNST completely eliminated stress-induced reinstatement of cocaine CPP, thus demonstrating the requirement for the BNST in this behavior in mice and extending the previous work examining alternate stressors in rats (Erb and Stewart, 1999; Erb et al., 2001; Leri et al., 2002; McFarland et al., 2004). It is important to note that the lidocaine infusion may have inhibited fibers of passage through the BNST, and this may have contributed to the behavioral effect on reinstatement. However, the finding that BNST inactivation simultaneously blunted cellular activation within the VTA and downstream components of reward circuitry strongly implicates BNST afferents to the VTA as integral to stress-induced reinstatement. Additionally, the microinfusion procedure may have led to diffusion of lidocaine into the lateral ventricles or sites dorsal to the BNST. However, our findings that infusions of lidocaine directly into the ventricles leads does not lead to alterations in forced swim behavior, whereas infusions into the BNST do, makes this interpretation unlikely. Differential effects in CREB-deficient mice implicate this as a critical molecular mechanism for stress-induced reinstatement within these specific neurons. Identifying gene transcription targets of CREB within the BNST could provide us with novel therapeutic agents for the treatment of stressinduced relapse.

\section{Conclusion}

CREB function within stress-reinstatement circuitry is necessary for the activation of cell populations involved in cocaine reinstatement by stress exposure. Comparisons of this activated circuitry between wild-type and $\operatorname{CREB} \alpha \Delta$ mutant mice revealed the
CREB-dependent circuits underlying stress-induced reinstatement. Local cellular inactivation studies identified CREBresponsive BNST afferents to the VTA as being necessary for swim-stress-induced reinstatement of cocaine-conditioned reward in mice. Identification of CREB target genes within these cell populations may provide novel therapeutic targets for stressinduced relapse. Together, this information advances our understanding of systems and cellular aspects of circuits underlying stress-induced drug relapse.

\section{References}

Blundell J, Adamec R (2007) The NMDA receptor antagonist CPP blocks the effects of predator stress on PCREB in brain regions involved in fearful and anxious behavior. Brain Res 1136:59-76.

Boutrel B, Kenny PJ, Specio SE, Martin-Fardon R, Markou A, Koob GF, de Lecea L (2005) Role for hypocretin in mediating stress-induced reinstatement of cocaine-seeking behavior. Proc Natl Acad Sci U S A 102:19168-19173.

Brown SA, Vik PW, McQuaid JR, Patterson TL, Irwin MR, Grant I (1990) Severity of psychosocial stress and outcome of alcoholism treatment. J Abnorm Psychol 99:344-348.

Brown SA, Vik PW, Patterson TL, Grant I, Schuckit MA (1995) Stress, vulnerability and adult alcohol relapse. J Stud Alcohol 56:538-545.

Conti AC, Cryan JF, Dalvi A, Lucki I, Blendy JA (2002) cAMP response element-binding protein is essential for the upregulation of brain-derived neurotrophic factor transcription, but not the behavioral or endocrine responses to antidepressant drugs. J Neurosci 22:3262-3268.

Corrigall WA (1987) Heroin self-administration: effects of antagonist treatment in lateral hypothalamus. Pharmacol Biochem Behav 27:693-700.

Coutureau E, Killcross S (2003) Inactivation of the infralimbic prefrontal cortex reinstates goal-directed responding in overtrained rats. Behav Brain Res 146:167-174

Curtis AL, Bello NT, Connolly KR, Valentino RJ (2002) Corticotropinreleasing factor neurones of the central nucleus of the amygdala mediate locus coeruleus activation by cardiovascular stress. J Neuroendocrinol 14:667-682.

Dewart T, Frank B, Schmeidler J (2006) The impact of 9/11 on patients in New York City's substance abuse treatment programs. Am J Drug Alcohol Abuse 32:665-672.

Erb S, Stewart J (1999) A role for the bed nucleus of the stria terminalis, but not the amygdala, in the effects of corticotropin-releasing factor on stressinduced reinstatement of cocaine seeking. J Neurosci 19:RC35(1-6).

Erb S, Salmaso N, Rodaros D, Stewart J (2001) A role for the CRFcontaining pathway from central nucleus of the amygdala to bed nucleus of the stria terminalis in the stress-induced reinstatement of cocaine seeking in rats. Psychopharmacology 158:360-365.

Franklin KBJ, Paxinos G (2007) The mouse brain in stereotaxic coordinates, Ed 3. San Diego: Academic.

Fumagalli F, Di Pasquale L, Caffino L, Racagni G, Riva MA (2007) Repeated exposure to cocaine differently modulates BDNF mRNA and protein levels in rat striatum and prefrontal cortex. Eur J Neurosci 26:2756-2763.

Geisler S, Zahm DS (2005) Afferents of the ventral tegmental area in the rat-anatomical substratum for integrative functions. J Comp Neurol 490:270-294.

Hamlin AS, Clemens KJ, McNally GP (2008) Renewal of extinguished cocaine-seeking. Neuroscience 151:659-670.

Harris GC, Wimmer M, Aston-Jones G (2005) A role for lateral hypothalamic orexin neurons in reward seeking. Nature 437:556-559.

Kalivas PW, McFarland K (2003) Brain circuitry and the reinstatement of cocaine-seeking behavior. Psychopharmacology 168:44-56.

Kalivas PW, Volkow ND (2005) The neural basis of addiction: a pathology of motivation and choice. Am J Psychiatry 162:1403-1413.

Kreibich AS, Blendy JA (2004) cAMP response element-binding protein is required for stress but not cocaine-induced reinstatement. J Neurosci 24:6686-6692.

Kreibich AS, Briand L, Cleck JN, Ecke L, Rice KC, Blendy JA (2009) Stressinduced potentiation of cocaine reward: a role for $\mathrm{CRF}(\mathrm{R} 1)$ and CREB. Neuropsychopharmacology 34:2609-2617.

Kwon MS, Seo YJ, Shim EJ, Choi SS, Lee JY, Suh HW (2006) The effect of single or repeated restraint stress on several signal molecules in paraven- 
tricular nucleus, arcuate nucleus and locus coeruleus. Neuroscience 142:1281-1292.

Leri F, Flores J, Rodaros D, Stewart J (2002) Blockade of stress-induced but not cocaine-induced reinstatement by infusion of noradrenergic antagonists into the bed nucleus of the stria terminalis or the central nucleus of the amygdala. J Neurosci 22:5713-5718.

Lu L, Zhang B, Liu Z, Zhang Z (2002) Reactivation of cocaine conditioned place preference induced by stress is reversed by cholecystokinin-B receptors antagonist in rats. Brain Res 954:132-140.

McFall ME, Mackay PW, Donovan DM (1992) Combat-related posttraumatic stress disorder and severity of substance abuse in Vietnam veterans. J Stud Alcohol 53:357-363.

McFarland K, Kalivas PW (2001) The circuitry mediating cocaine-induced reinstatement of drug-seeking behavior. J Neurosci 21:8655-8663.

McFarland K, Davidge SB, Lapish CC, Kalivas PW (2004) Limbic and motor circuitry underlying footshock-induced reinstatement of cocaine-seeking behavior. J Neurosci 24:1551-1560.

Nazarian A, Sun WL, Zhou L, Kemen LM, Jenab S, Quinones-Jenab V (2009) Sex differences in basal and cocaine-induced alterations in PKA and CREB proteins in the nucleus accumbens. Psychopharmacology 203:641-650.

Nestler EJ (2005) Is there a common molecular pathway for addiction? Nat Neurosci 8:1445-1449.

Nestler EJ (2008) Review. Transcriptional mechanisms of addiction: role of DeltaFosB. Philos Trans R Soc Lond B Biol Sci 363:3245-3255.

Nestler EJ, Hope BT, Widnell KL (1993) Drug addiction: a model for the molecular basis of neural plasticity. Neuron 11:995-1006.

Olds J (1962) Hypothalamic substrates of reward. Physiol Rev 42:554-604.

Olds ME (1979) Hypothalamic substrate for the positive reinforcing properties of morphine in the rat. Brain Res 168:351-360.

Ouimette P, Coolhart D, Funderburk JS, Wade M, Brown PJ (2007) Precipitants of first substance use in recently abstinent substance use disorder patients with PTSD. Addict Behav 32:1719-1727.

Peters J, LaLumiere RT, Kalivas PW (2008) Infralimbic prefrontal cortex is responsible for inhibiting cocaine seeking in extinguished rats. J Neurosci 28:6046-6053.

Rhodes SE, Killcross AS (2007) Lesions of rat infralimbic cortex enhance renewal of extinguished appetitive Pavlovian responding. Eur J Neurosci 25:2498-2503.

Rhodes SE, Killcross S (2004) Lesions of rat infralimbic cortex enhance re- covery and reinstatement of an appetitive Pavlovian response. Learn Mem 11:611-616.

Roberts DC, Koob GF (1982) Disruption of cocaine self-administration following 6-hydroxydopamine lesions of the ventral tegmental area in rats. Pharmacol Biochem Behav 17:901-904.

Shaham Y, Shalev U, Lu L, De Wit H, Stewart J (2003) The reinstatement model of drug relapse: history, methodology and major findings. Psychopharmacology 168:3-20.

Shalev U, Morales M, Hope B, Yap J, Shaham Y (2001) Time-dependent changes in extinction behavior and stress-induced reinstatement of drug seeking following withdrawal from heroin in rats. Psychopharmacology 156:98-107.

Sheng M, Greenberg ME (1990) The regulation and function of c-fos and other immediate early genes in the nervous system. Neuron 4:477-485.

Stewart J (1984) Reinstatement of heroin and cocaine self-administration behavior in the rat by intracerebral application of morphine in the ventral tegmental area. Pharmacol Biochem Behav 20:917-923.

Walters CL, Blendy JA (2001) Different requirements for cAMP response element binding protein in positive and negative reinforcing properties of drugs of abuse. J Neurosci 21:9438-9444.

Walters CL, Kuo YC, Blendy JA (2003) Differential distribution of CREB in the mesolimbic dopamine reward pathway. J Neurochem 87:1237-1244.

Wang B, You ZB, Rice KC, Wise RA (2007) Stress-induced relapse to cocaine seeking: roles for the $\mathrm{CRF}(2)$ receptor and CRF-binding protein in the ventral tegmental area of the rat. Psychopharmacology 193:283-294.

Wang J, Fang Q, Liu Z, Lu L (2006) Region-specific effects of brain corticotropin-releasing factor receptor type 1 blockade on footshockstress- or drug-priming-induced reinstatement of morphine conditioned place preference in rats. Psychopharmacology 185:19-28.

Wang X, Cen X, Lu L (2001) Noradrenaline in the bed nucleus of the stria terminalis is critical for stress-induced reactivation of morphineconditioned place preference in rats. Eur J Pharmacol 432:153-161.

Xu Y, Ku B, Tie L, Yao H, Jiang W, Ma X, Li X (2006) Curcumin reverses the effects of chronic stress on behavior, the HPA axis, BDNF expression and phosphorylation of CREB. Brain Res 1122:56-64.

Zavala AR, Browning JR, Dickey ED, Biswas S, Neisewander JL (2008) Region-specific involvement of AMPA/Kainate receptors in Fos protein expression induced by cocaine-conditioned cues. Eur Neuropsychopharmacol 18:600-611. 